\title{
Progressing Gender Equality Post-2015: Harnessing the Multiplier Effects of Existing Achievements
}

\author{
Nicola Jones, Rebecca Holmes and Jessica Espey
}

\begin{abstract}
This article argues that international efforts to progress gender equality now and post-2015 need to build on the achievements of the MDGs and other international frameworks, but simultaneously address the gender dynamics that underpin the root causes of poverty. The first half of the article seeks to unpack the ways in which gender inequalities underpin five clusters of MDGs: poverty and sustainable development; service access; care and caregiving; voice and agency; international partnerships and accountability. The analysis then turns to highlight the importance of harnessing the momentum from other global initiatives such as CEDAW (Convention on the Elimination of All Forms of Discrimination against Women) and the Beijing Platform for Action to promote more fundamental change including: the establishment of a more powerful UN agency to champion gender equality; the institutionalisation of gender budgeting and genderresponsive aid effectiveness approaches; and the promotion of gender-sensitive social protection to tackle gender-specific experiences of poverty and vulnerability.
\end{abstract}

\begin{abstract}
1 Introduction
The Millennium Declaration of September 2000 marked a momentous international commitment to poverty reduction, with 189 nations agreeing to the achievement of eight Millennium Development Goals (MDGs) by 2015. However, while the MDGs have effectively highlighted specific policy challenges within the broader context of poverty reduction, reducing poverty is complex and non-linear. For sustainable poverty reduction to occur now and post-2015, tackling the root causes of poverty while recognising that experiences of poverty and vulnerability differ greatly by sex, age, ethnic group, etc. is urgently needed.
\end{abstract}

Gender inequality can both cause and perpetuate poverty and vulnerability especially for women and girls. Achieving greater gender equality therefore can help reduce poverty and vulnerability and also contribute to pro-poor growth. Given the MDG focus on addressing important development challenges, it is vital that tackling gender inequalities are addressed throughout the Goals. However, gender inequalities are only currently an explicit focus of MDGs 3 and 5. MDG 3 on Gender Equality measures the ratio of girls to boys in education; the share of women in wage employment in the non-agricultural sector; and the proportion of seats held by women in national legislatures. MDG 5 on Maternal Mortality and Reproductive Health focuses on reducing the maternal mortality ratio by three-quarters and since 2005 on achieving universal access to reproductive health.

Although an important first step, the current focus on gender equality is narrow and sidelines other gender-specific risks and vulnerabilities, roles and responsibilities and power dynamics. In isolation from a gender-responsive approach to the other Goals this focus is unlikely to lead to girls' and women's empowerment and gender equality, nor likely to effectively tackle the development challenges necessary to enable sustainable poverty reduction now and after 2015. Moreover, these limitations are compounded by the fact that not only are the indicators for the other Goals gender-blind, but 
rhetorical support for gender mainstreaming notwithstanding, the gender dynamics that cut across the other Goals have remained relatively invisible in policy dialogues on the MDGs (Subrahmanian 2004; Johnson 2005).

In this article, we discuss the ways in which gender relations underpin four clusters of Goals - those that deal with poverty and sustainable development, service access, care and caregiving, and voice and agency - and suggest how to promote an interlinked gender-sensitive approach to MDG achievement. This approach not only seeks to highlight ways through which we might more effectively accelerate progress towards the MDGs over the remaining five years, but suggests strategies that will take us beyond 2015, so that we might progress gender equality in a post-MDG context. In particular, we focus on forging synergies with existing international gender-related commitments; gender-sensitive budgeting; the creation of a unified and wellresourced UN agency mandated to address gender inequalities, and gender-sensitive social protection interventions.

\section{MDGs through a gender lens}

\subsection{Poverty and sustainable development}

Eradicating extreme poverty and hunger (MDG 1) and ensuring environmental sustainability (MDG 7) are two of the least achieved MDGs. Up to 443 million people live in chronic poverty (CPRC 2008), the majority of whom live in rural areas and are highly dependent on agriculture for their livelihoods, either directly or indirectly. At the same time, rapid urbanisation is creating and compounding poverty and vulnerability for people living in urban slums (CPRC 2008). In many parts of the world, a large and growing proportion of the agricultural workforce are women. In most countries, women are also responsible for household food production and consumption. In an ever-evolving context of opportunities and threats, from globalisation to climate change, the links between women's empowerment, natural resource management and food security are vital - yet these links are often overlooked (Pearl 2003; Quisumbing et al. 2008). Women's ownership of and control over natural and productive resources, such as land, and higher education levels leads to greater productivity (World Bank 2007a, 2001) yet many women across the world are prevented from owning productive assets and achieving educational attainment because of prevailing social/cultural attitudes and discriminatory laws. This unequal access to assets and opportunities in turn has implications for the ability of women to adapt to climate change. Women are often less able to adapt than men due to lower income-generating potential, lower education levels, limited or no access to land rights and less access to extension agents and related agricultural technologies (Lambrou and Piana 2006). Moreover, while globalisation has opened new opportunities in labour markets for many women, they continue to earn less than men, even in similar jobs (Lambrou and Piana 2006), and are overrepresented in the casual and in the informal sector, with little access to social security or predictable income (Kabeer 2008; Lund and Srinivas 2000).

\subsection{Access to services}

Access to services is another critical area of poverty reduction but enormous challenges remain. Currently, approximately 64 per cent of MDG targets for service-related Goals $(2,3,6,7)$ are 'off track'. ${ }^{1}$ Examining these goals through a gender lens highlights the importance of exploring the ways in which men and women, girls and boys face different challenges in accessing quality services. In the case of the health-related Goals $(4,5,6)$, some challenges are related to biological differences (such as divergent disease burdens) which are not accorded sufficient attention in policy design - for instance, greater susceptibility to malaria on the part of pregnant women or higher risk of tuberculosis on the part of men (Diagne et al. 2000; Bhushan 2008). In other cases, a combination of biological and social factors may be overlooked because of narrow sectoral approaches to service delivery. Telling examples include: (1) the growing 'feminisation' of HIV/AIDS stemming from not only women's greater biological susceptibility to infection, but also their relative lack of sociocultural power which constrains the ability of, especially young women, to negotiate safe sex (UNFPA 2005), ${ }^{2}$ and (2) men's greater susceptibility to tobacco-induced illnesses stemming from notions of masculinity and forms of social interaction that associate smoking with 'macho' behaviour (Bhushan 2008).

Other challenges relate to socially constructed gender roles, including the dual caregiver and productive responsibilities that women typically shoulder. In this regard, time poverty is a critical 
variable, which disproportionately affects women. In Brazil, for instance, recent studies suggest that 90 per cent of women spend an average of 20 hours a week on unpaid domestic chores. By contrast, only 45 per cent of men spend an average of seven or more hours a week on domestic duties (Jones and Baker 2008). Time poverty may significantly affect MDG 6 (combat HIV/AIDS, malaria and tuberculosis), for example by hindering women's access to healthcare if clinics are far away and affordable childcare unavailable. Similarly, time poverty is also closely related to MDG 7 (environmental sustainability, especially access to basic sanitation and safe drinking water). Typically women and girls are responsible for timeintensive collection of water and firewood, but investments in clean water, sanitation, timesaving technologies and skills training can improve sustainable resource management, food security, nutrition and health, and allow more opportunities for girls and women to engage in educational and other productive activities.

Another constraint that impinges upon assessing progress towards equitable service delivery is the limited routine use of gender-sensitive indicators. While the ambition to provide universal primary education (MDG 2) has been heralded as a highly attainable Goal, especially relative to other MDGs, Indicators to measure progress do not acknowledge the linkages between gender and quality of education, i.e. that enrolment does not necessarily reflect consistent attendance or completion rates. This is particularly relevant for an assessment of sexual parity in education (MDG 3). Girls often face a range of gender-specific barriers in attending school, especially once they reach adolescence. These include lower attendance and higher drop-out rates due to household chores, caregiving responsibilities and pressures for early marriage, parental preference for sons' education, and the deterrent effect that risk of sexual violence en route to school or within schools may have (Jones et al. 2008b).

\subsection{Care and caregiving}

A critical contribution of feminist thought to development has been to raise the visibility and value of care. The call has been to reconceptualise care across the life-course as a joint responsibility of society and the state, rather than one solely shouldered by women
(Razavi 2007). Yet despite slow progress on MDGs 4 (child mortality) and 5 (maternal mortality) (see below) discussions linking MDG attainment and the need for better and more gender-sensitive systems of care have been limited. Thinking about this problem from a gender and care perspective highlights the importance of moving beyond a reliance on technology (such as vaccines) and infrastructure (e.g. new health clinics) in isolation, and ensuring that policies and programmes are informed by a clear analysis of underlying social determinants, including gender (Sen and Östlin 2007). Recent research commissioned by the GAVI Alliance, for instance, highlighted that contrary to previous assumptions about the gender neutrality of immunisation services against childhood diseases, important gender differences exist in coverage rates. While girls are often disadvantaged in South Asia due to son preference, boys, especially in parts of West Africa, are not being immunised out of fear of sterility risks. Moreover, efforts to reach the poorest children will need to pay particular attention to gender-related barriers as these are often more prevalent in contexts with high resource constraints, low education levels and spatial poverty (Jones et al. 2008a).

Providing equitable access to quality maternal and reproductive healthcare necessitates a comprehensive health systems strengthening approach, including tackling gendered power relations and resource constraints that hinder health-seeking behaviour. Maternal mortality remains alarmingly high in many developing countries, especially in sub-Saharan Africa. In Sierra Leone, for instance, a woman has a one in eight chance of dying during pregnancy or childbirth, whereas in the industrialised world, the risk of maternal death is one in 8,000 .

Moreover, while some progress has been made in reducing child deaths, UNICEF's State of the World's Children Report 2008: Child Survival warns that failing to improve maternal health threatens the chances of reaching MDG 4 because of the unrealised double dividend between women's empowerment and improved child health, nutritional and educational outcomes (UNICEF 2007). Indeed, the majority of countries (spanning those with weak governance and severe resource constraints to stable democracies and those with positive growth) are significantly off-track on MDG 5. 
In Ghana, for instance, where positive economic growth and political stability have earned the country the label 'West Africa's shining star', the lack of progress in reducing maternal mortality rates over the 2000s was recently recognised as a 'national emergency' at a high level governmentdonor forum. Although health insurance fee exemptions for pregnant women in Ghana have now been introduced, ensuring adequate and affordable care will necessitate a more comprehensive approach. This should include strategies to redress adolescent girls' and women's limited decision-making over healthcare expenditures, taking into account restrictions on female mobility (e.g. by funding mobile clinics with adequate female personnel so as to address cultural and religious norms, especially in South Asia and the Middle East). Cultural attitudes that reinforce power relations and perpetuate harmful traditional practices (e.g. through educational campaigns to discredit nutritional taboos during pregnancy and to promote women's right to quality reproductive health services) should also be addressed.

In the case of child mortality, comprehensive change at the micro- and macro-levels is necessary. Recent World Health Organization (WHO) reviews have demonstrated that involving men in programmes that encourage them to participate more actively in the support and care of their children lead to significantly better child and maternal health outcomes. However, such efforts require sensitive framing in order to effectively reorient prevailing notions of masculinity that are often incompatible with caring roles (WHO 2007). At the macro-level, holding governments and development partners to account for demonstrating progress in supporting care services and caregivers, is a vital but largely neglected area. Efforts to collect, analyse and regularly report on sexdisaggregated data are essential, as are scalingup and institutionalising pro-poor and genderresponsive budget analysis and monitoring approaches.

\subsection{Voice and agency}

Promoting the ability of women to articulate their views in a meaningful way (voice) and to become the agents of their own empowerment (agency) is vital to overcome engrained sociocultural conditioning and the gendered division of labour in private and public spheres, whereby women and women's interests are typically relegated an inferior and largely invisible status. As Goetz and Nyamu Musembi (2008: 7-8) argue:

Women's 'voice' has been judged to be unreliable, a notion that is present in the cultural milieu of many societies. Even worse, women's 'voice' has in the past been seen as the opposite of what male voice represents: reasoned argument, reasonableness - the basic elements of democratic deliberation and civilization ... In consequence, some of the issues about which some women have much to say because the issues are a major part of their lives - for instance children's welfare, basic livelihoods and food crops, domestic violence, reproductive health - have for a long time been excluded from political agendas, not seen as matters for public deliberation or issues to be addressed through social policy, justice institutions, or economic policy.

MDG 3 deals with two important tools and arenas for empowerment - education and national political representation - but experience from Latin America, where quotas for women in the legislature are now widespread and women's higher education rates increasingly exceed those of men, demonstrates that empowerment necessitates a more comprehensive approach (Dahlerup 2006). This includes efforts to improve women's access to resources such as access to credit, entrepreneurial training, inheritance and land rights, and their capacity to make use of them, for example through anti-discrimination and gender-based violence legislation, gender-aware justice systems and adequately resourced government machineries mandated to improve gender inequality.

It also necessitates an ongoing articulation between women's civil society collective action and formal political representatives if women's voices are to have a sustainable transformative impact. For instance, although women's involvement in anti-dictatorship movements in Latin America and East Asia in the 1970s and 1980s contributed to democratic regime changes in the late 1980 s/early 1990 s, these gains proved limited in duration once the political transitions receded, and women were largely marginalised from formal representative politics (e.g. Jaquette 
and Wolchik 1998; Jones 2006). In other words, women's collective action to date has played a critical role in shaping new policy agendas (e.g. raising the visibility of family violence, reproductive health issues, the importance of investing in the care economy), but internationally the record in securing sustainable and institutionalised change has proven considerably more challenging (Goetz and Nyamu Musembi 2008).

\subsection{International partnerships and accountability}

MDG 8, which focuses on improved international aid and cooperation in the fields of science and technology, private sector development, trade and employment rights for youth, could also offer an important window of opportunity for supporting women's voice and agency. On the one hand, the formulation of MDG 8 has been roundly criticised for setting few Indicators against which to measure the progress of Northern actors' contribution to the MDGs, and for the absence of a gender perspective (Moser 2007). On the other, only by recognising the ways in which global macroeconomic and political issues are gendered, are we likely to find effective and sustainable solutions to achieving the other goals. Recent Free Trade Agreements in Latin America, for instance, have provided general commitments to ensuring the implementation of equal employment legislation ${ }^{3}$ but concerted action by governmental and non-governmental actors in the North and South is required to ensure that their operationalisation is effectively realised (Jones and Baker 2008). On the aid front, the recognition of gender equality as a cross-cutting issue in the Paris Declaration and the Organisation for Economic Co-operation on Development's (OECD) Development Assistance Committee (DAC) overseas development assistance (ODA) gender marker are important first steps. New modalities to provide civil society groups working on gender equality issues with adequate resources and capacity strengthening support also need to be sought so that their perspectives can be represented in policy dialogues. Equally importantly, with a growing trend towards public-private partnerships to deliver international development goods (e.g. the Global Fund to Fight AIDS, Tuberculosis and Malaria, PEPFAR), innovative approaches to raise the awareness of private sector actors about gender issues, should not be overlooked if such partnerships are to be premised on common values and goals.

\section{Promoting gender equality by capitalising on hard-fought gains}

Tackling the gender gaps in the MDGs and implementing sustainable mechanisms to ensure gender equality requires not just another set of piecemeal reforms, but a more fundamental reworking of the international aid architecture and modalities so that future development efforts will not repeat the mistakes of the past. Given the achievements of the MDG agenda in some areas and regions, and the comprehensive international frameworks that have already been established to promote gender equality, post2015 initiatives do not necessitate a reinvention of the wheel. It will be more effective to build on current successes, better promote existing frameworks (such as GEDAW, the Convention on the Elimination of All Forms of Discrimination against Women, and the Beijing Platform for Action) and take concrete steps to integrate gender equality into all development strategies and monitoring and evaluation efforts. Here we focus on four areas that we believe are particularly important for MDG achievement and beyond: creating synergies with international commitments to gender equality; establishing a more powerful UN agency to champion gender equality; institutionalising gender budgeting and gender-responsive aid effectiveness approaches; and promoting gendersensitive social protection. These initiatives should be underwritten by a commitment to MDG 8's calls for strengthened global partnerships in international development.

\subsection{Maximising synergies with existing international frameworks}

An understanding of how improvements in gender equality - from improved access to resources and asset ownership, to more gendersensitive service delivery and support for caregiving responsibilities, to greater voice and agency - impact poverty reduction and natural resource management needs to resonate across all the Goals between now and 2015, and equally importantly to inform post-2015 development strategies. Better consideration of gendered dynamics throughout policy formation and improved cross-sectoral programming may be encouraged by demonstrating, for example, the positive spill-over effects between girls' and women's rights and broader development goals, whether it be links between female education and improved child wellbeing and breaks in 
inter-generational poverty transfers (UNICEF 2006), or the correlation between investments in women's empowerment and economic productivity (World Bank 2007b).

As part of the call for strengthened global partnerships in international development, we also need to compliment the emphases in the MDGs with a renewed commitment to existing gender-related international rights-based frameworks, including CEDAW and the Beijing Platform for Action. These frameworks spotlight gender-specific risks and barriers that are largely invisible in the MDGs but critical to their achievement - such as gender-based violence, harmful traditional practices (e.g. female genital mutilation and early marriage), and the particular challenges facing female youth in finding decent employment. Equally importantly, they underscore the accountability of national governments and the international community to ensure that the necessary resources and institutional mechanisms are in place to achieve gender-based rights. For instance, legislation on gender discrimination needs to be seen as a first step rather than the end of the road, and backed by capacity-building support for judicial and police personnel as well as resources to undertake necessary community mobilisation and awareness work.

\subsection{Establishing an international gender champion}

Gender mainstreaming efforts have resulted in considerable achievements; UN agencies have become better at capacity building, many programmes now feature performance indicators and the OECD DAC has encouraged the use of gender equality markers in programme delivery (OECD 2007). However, mainstreaming efforts have also been rightly criticised for being narrowly technocratic and lacking the consistent financial and human resources necessary to deliver more transformative changes and have suffered in some cases from policy dilution. There continues to be a lack of systematic gender analysis underpinning most development initiatives, and bilateral and multilateral agencies are frequently unable to effectively link gender equality policies to broader organisational goals (e.g. NORAD 2006).

At the international level, given the institutional weaknesses which have plagued the United Nations Development Fund for Women,
UNIFEM, (and its three partner UN agencies Division for the Advancement of Women, Office of the Special Advisor on Gender Issues, and the International Research and Training Institute for the Advancement of Women), the creation of a well-resourced, independent agency focused on gender equality and women's empowerment, with operational and oversight capacity and universal country presence would be the best way to promote effective gender mainstreaming across the UN system, as well as to monitor the effective implementation of gender goals and commitment to gender conventions within broader development efforts. There is movement within the UN for such a reform to create such a 'super-agency'. This belated action has been driven by the findings of a high-level panel which in 2006 gave a damning assessment of the UN systems for women and gendered issues and since 2006, by the campaigning of over 300 nongovernmental organisations (NGOs) under the umbrella of the Gender Equality Architecture Reform, or GEAR, campaign. But key to the success of this reform (subject to it being passed) will be the need for considerable and sustained funding above and beyond that currently dedicated to the four disparate UN agencies for women.

\subsection{Gender budgeting and aid effectiveness}

The aid effectiveness agenda has been a major game-changer since the Paris High Level Meeting on Aid Effectiveness (High Level Forum 2005) and is likely to remain a major development focus after 2015. As such, the recognition of gender equality as a cross-cutting issue in the Paris Declaration and the DAC's gender marker system to assess the contribution of ODA to gender equality goals have been important first steps. However, early assessments of the move to General Budget Support suggest that more proactive measures are needed, including greater opportunities for civil society to participate in national priority setting and institutionalised incentive structures for officials to demonstrate progress on improved gender equality outcomes (OECD 2008). It is also important that the DAC Guiding Principles for Aid Effectiveness, Gender Equality and Women's Empowerment are widely disseminated and monitored in order to ensure that the outcomes of the Accra High Level Forum on Aid Effectiveness are implemented in a genderresponsive manner by donor agencies and 
partner country governments alike. A key focus throughout this document is the need to strengthen accountability mechanisms, indicators, data collection and processes, as well as gender analysis capacities in order to hold both donors and partner governments to account for their work to reduce gender gaps and empower women.

Gender budgeting constitutes an important tool to help minimise the problem of policy evaporation. The budget is a crucial policy statement and an important instrument in government planning (Budlender 2004). Given that government policy choices about revenue and expenditure impact people in a number of ways - which often differ for women and girls budget policies and processes must be equally bound by CEDAW principles of nondiscrimination, equality, participation and modification of social and cultural patterns of conduct. Gender budgeting initiatives involving alliances between a range of NGOs, government organisations and international agencies now exist in more than 40 countries in the developed and developing world. ${ }^{4}$ Efforts have ranged from the non-governmental Tanzanian Gender Networks Programme, which has effectively integrated gender budgeting tools into the governmental Public Spending Review and the Poverty Reduction Strategy Paper (PRSP) process, to the National Commission on the Role of Filipino Women, which successfully oversaw the development of a Gender and Development Budget Policy that requires government agencies and local governments to set aside at least 5 per cent of their development budget for gender and development projects. ${ }^{5}$ Such initiatives have succeeded in raising the visibility and allocation of resources to gender equality issues and the importance of going beyond legislative and policy frameworks if real transformation in gender relations is to be achieved.

\subsection{Promoting gender-sensitive social protection}

Social protection ${ }^{6}$ is a policy approach that presents an opportunity to help achieve the MDGs in a synergistic and gender-sensitive manner and to put in place comprehensive structures to progress gender equality after 2015. Conceptualised as reducing household vulnerability and chronic economic and social deprivation, social protection strategies are increasingly being put in place across the world to cushion the impact of shocks and to help poor households take advantage of the opportunities that globalisation and economic growth may present.

Social protection has the potential to maximise synergies across the MDGs by reducing poverty and inequality through strengthening access to and demand for quality basic and social services, supporting economic productivity, and facilitating a better balance between caregiving and productive work responsibilities. Importantly, many of the social protection programmes attracting international attention are designed to incorporate gender needs. Cash transfer schemes in Brazil and Mexico, for instance, have already had positive improvements on the educational, health and nutritional outcomes of millions of extremely poor children, especially girls, by targeting cash payments to the caregiver (typically the mother) and providing higher incentives for girls' schooling. Evaluations to date also suggest that these programmes are supporting women's empowerment by increasing their control and responsibility of resources and decision-making power within the household (e.g. Agende Actions 2006).

Some gender analysts, however, caution that while current programme design addresses women's practical gender needs (immediate caregiving responsibilities), they are making only a limited contribution to women's strategic gender interests (promoting a more egalitarian division of labour between men and women) by reinforcing women's traditional caring roles and underestimating time constraints (e.g. Molyneux 2006). Moreover, few programmes to date have answered the call for 'transformative' social protection, including measures to address the gender-specific social risks and vulnerabilities which household members face - including discrimination and social exclusion, violence and time poverty (Devereux and Sabates-Wheeler 2004).

Taking a gender-sensitive approach to social protection will require refocusing programme design and encouraging agencies responsible for livelihood promotion and protection, basic and social services and the enforcement of antidiscrimination legislation to work together to achieve the MDGs and long-term gender equality. As such it will necessitate an institutional (rather than piecemeal) approach, 
involving strengthening local institutions, committed long-term funding and a strategy for scaling-up interventions in order to address equity concerns. A refocused social protection agenda will also need to take account of intrahousehold inequalities, especially decisionmaking power and access/ownership/control over resources; recognise the importance of social reproduction including unpaid caregiving and household management work, as well as the diversity of family arrangements; and understand and seek to address the distinct and often unequal experiences of men and women in the labour market (Antanopoulos 2008).

A refocused social protection agenda may include some of the following concrete policy and programme measures. In order to improve the position of caregivers, programmes may provide a caregiver allowance in recognition of the costs of care (e.g. Mexico's new subsidised estancia or public crèche programme), and/or seek to provide community childcare in public works schemes to allow women equal access to productivity-enhancing safety nets and to prevent younger girls from taking on additional domestic responsibilities (e.g. as provided for in the programme implementation manual of Ethiopia's Productive Safety Net Programme (PSNP) and India's National Rural Employment Guarantee Scheme). In order to uphold and to promote achievements in education, programmes might fund stipends for girls to reinforce the importance of girls' education (such as the Girls' Education Stipend scheme in Bangladesh). Support for access to basic services and to challenge abusive environments (e.g. in school, in the home) may include awareness-raising programmes and include financial support for women and children escaping abusive environments (e.g. NGO pilot initiatives in Ghana). Women and men should be given the opportunity to be programme participants and to be involved in the design and evaluation of social protection programmes to ensure relevance and maximum efficacy (e.g. as included in the PSNP provisions). Other capacity-building efforts could include supporting gender awareness and gender analysis training for programme staff, so as to be better able to identify gender-specific risks and vulnerabilities to be tackled through programme interventions. Finally, it will be essential to maintain a rigorous monitoring and evaluation system, underpinned by a baseline with sex-disaggregated data, and to invest in a centralised database that facilitates monitoring of programme participants' wellbeing status as well as providing linkages to complementary services (e.g. access to microcredit and microentrepreneurial training for women).

\subsection{Next steps for donors and national policymakers}

Overall, our analysis suggests that there are a number of both short- and medium-term actions that donors and policymakers could take in order to promote more gender-responsive development patterns.

\section{Donors}

- Encourage more strategic attention to gender equality considerations among development partner countries by highlighting the returns of investing in girls and women's rights, i.e. the correlation between investments in empowerment and economic productivity in country situational analyses and priority dialogue areas

- Demonstrate renewed commitments to CEDAW and the Beijing Platform for Action in country and headquarter-level strategy, programme and evaluation documents

- Provide incentives for greater integration of gender analysis in all development initiatives by governmental and non-governmental actors so that gender programmes are not siloed

- Support the new UN gender equality agency both in terms of political and financial commitments

- Disseminate and reinforce the DAC Guiding Principles for Aid Effectiveness, Gender Equality and Women's Empowerment.

\section{National policymakers}

- Renew and uphold commitments made in ratifying CEDAW and the Beijing Platform for Action

- Create institutional incentives for progress and reporting on gender equality outcomes at the national and sub-national levels

- Strengthen and institutionalise gendersensitive budgeting initiatives so as to increase the resources invested in as well as the visibility of gender equality considerations

- Refocus the national social protection agenda to ensure programme design, implementation and evaluation is more gender-responsive

- Set up and maintain a national monitoring and evaluation system on gender equality issues, underpinned by a baseline with sexand age-disaggregated data. 


\section{Notes}

1 Countries that have been referred to as 'off track' had attained poor or middle status within the specified Goal on the MDG Monitor website as of 18 August 2008. Middle status is classified as 'possible to achieve if changes are made.' MDG Monitor levels are derived from UNSD (United Nations Statistical Division) statistics as of 18 August 2008.

2 Young women represent 67 per cent of all new cases of HIV among people aged 15-24 in developing countries. See: www.unfpa.org/ swp/2005/english/ch4/chap4_page 1.htm

3 Examples of commitments to gender equality within recent Free Trade Agreements in the region include:

(a) The different MERCOSUR fora are responsible for 'taking gender into account in the planning, elaboration and implementation of their activities, with the objective to guarantee equality and equity among the genders'.

\section{References}

Agende Actions in Gender, Development and Citizenship (2006) The Bolsa Familia Programme and the Tackling of Gender Inequalities. The Challenge of Promoting the Reordering of the Domestic Space and Women's Access to the Public Space, Research Report presented to the Ministry of Social Development and the Fight Against Hunger and Department for International Development, Brazil

Antanopoulos, R. (2008) The Unpaid Care Work-Paid Work Connection, Working Paper 541, July, The Levy Economics Institute, www.levy.org/pubs/wp_541.pdf (accessed 12 November 2009)

Bhushan, Anjana (2008) Gender and Health: A Framework for Analysis and Action, 13th Training Course of New Health Leaders, 3 September, World Health Organization/WPRO

Budlender, D. (2004) Expectations Versus Realities in Gender-responsive Budget Initiatives, Geneva: United Nations Research Institute for Social Development

CPRC (2008) The Chronic Poverty Report 2008-9: Escaping Poverty Traps, Manchester: Chronic Poverty Research Centre

Dahlerup, Drude (ed.) (2006) Women, Quotas and Politics, New York: Routledge, Taylor and Francis Group

Devereux, S. and Sabates-Wheeler, R. (2004) Transformative Social Protection, IDS Working Paper 232, Brighton: IDS (b) In the Peru-US FTA there is a provision for the 'development of programs on gender issues, including the elimination of discrimination in respect of employment and occupation'.

(c) In the NAFTA 'The Council shall promote cooperative activities between the Parties, as appropriate regarding: The equality of women and men in the workplace'.

4 See: www.wbg.org.uk/GBA_Inter.htm

5 See: www.gender-budgets.org/content/view/ $144 / 153$

6 The Joint Statement on Advancing ChildSensitive Social Protection defines social protection as follows: 'Social protection is generally understood as a set of public actions that address poverty, vulnerability and exclusion as well as provide means to cope with life's major risks throughout the life cycle' (DFID et al. 2009: 1).

DFID, HelpAge International, Hope \& Homes for Children, Institute of Development Studies, International Labour Organization, ODI, Save the Children UK, UNDP, UNICEF and the World Bank (2009) Advancing Child Sensitive Social Protection, Joint Statement, August, www.odi.org.uk/resources/download/ 3715.pdf (accessed 12 November 2009)

Diagne, N.; Roger, C.; Sokhna, C.S.; Tall, A.; Fontenille, D.; Roussihon, C.; Spiegel, A. and Trape, J.F. (2000) 'Increased Susceptibility to Malaria During the Early Postpartum Period', New England Journal of Medicine 343.9: 598-603

Goetz, Anne-Marie and Nyamu Musembi, Celestine (2008) 'Voice and Women's

Empowerment: Mapping a Research Agenda' in Pathways of Women's Empowerment, Voice and Women's Empowerment: Mapping a Research Agenda, Working Paper 2, www.research4development.info/Search ResearchDatabase.asp?OutputID = 178682 (accessed 12 November 2009)

High Level Forum (2005) Paris Declaration on Aid Effectiveness: Ownership, Harmonisation, Alignment, Results and Mutual Accountability, Paris, France, 28 February-2 March

Jacquette, Jane S. and Wolchik, Sharon L. (eds) (1998) Women and Democracy: Latin America and Central and Eastern Europe, Baltimore: Johns Hopkins University Press

Johnson, R. (2005) 'Not a Sufficient Condition: The Limited Relevance of the Gender MDG 
to Women's Progress', Gender and Development 13.1: 56-66

Jones, Nicola (2006) Gender and the Political Opportunities of Democratization in South Korea, New York: Palgrave Macmillan

Jones, N. and Baker, H. (2008) Untangling Links Between Trade, Poverty and Gender, ODI Briefing Paper, London: Overseas Development Institute

Jones, N.; Walsh, C. and Buse, K. (2008a) Gender and Immunisation: A Knowledge Stocktaking Report, report commissioned by the GAVI Alliance Secretariat, London: Overseas Development Institute

Jones, N.; Moore, K.; Villar, E. and Broadbent, E. (2008b) 'Painful Lessons: The Politics of Preventing Sexual Violence and Bullying at School', commissioned report by Plan, London: Overseas Development Institute Kabeer, N. (2008) Mainstreaming Gender in Social Protection for the Informal Economy, London: Commonwealth Secretariat

Lambrou, Yianna and Piana, Grazia (2006) Gender: The Missing Component of the Response to Climate Change, Rome, Italy: Food and Agriculture Organization

Lund, F. and Srinivas, S. (2000) Learning from Experience: A Gendered Approach to Social Protection for Workers in the Informal Sector, Geneva: International Labour Organization

Molyneux, M. (2006) 'Mothers at the Service of the New Poverty Agenda: Progresa/ Oportunidades, Mexico's Conditional Transfer Programme', Social Policy and Administration 40.4: 425-49

Moser, A. (2007) Gender and Indicators, Bridge Cutting Edge Pack, Brighton: IDS

NORAD (2006) Lessons from Evaluations of Women and Gender Equality in Development Cooperation, Synthesis Report 2006/1, Oslo: Norwegian Agency for Development Cooperation OECD (2008) Gender Equality, Women's

Empowerment and the Paris Declaration on Aid Effectiveness: Finding the Entry Points, Issues Brief 2, DAC Network on Gender Equality, Paris: Organisation for Economic Co-operation and Development

OECD (2007) Gender Equality and Aid Delivery: 'What has Changed in Development Co-operation Agencies since 1999?', Paris: Organisation for Economic Co-operation and Development
Pearl, R. (2003) Common Ground: Women's Access to Natural Resources and the UN MDGs, New York: Women's Environment and Development Organisation (WEDO)

Quisumbing, Agnes R.; Meinzen-Dick, Ruth Suseela; Bassett, Lucy; Usnick, Michael; Pandolfelli, Lauren; Morden, Cheryl and Alderman, Harold (2008) Helping Women Respond to the Global Food Price Crisis, Policy Brief 7, Washington DC: International Food Policy Research Institute

Razavi, S. (2007) The Political and Social Economy of Care in a Development Context: Conceptual Issues, Research Questions and Policy Options, UNRISD Working Paper 3, Geneva: United Nations Research Institute for Social Development Sen, G. and Östlin, P. (2007) Unequal, Unfair, Ineffective and Inefficient: Gender Inequity in Health: Why it Exists and How We Can Change it, Final Report to the WHO Commission on Social Determinants of Health, Women and Gender Equity Knowledge Network

Subrahmanian, R. (2004) 'Promoting Gender Equality', in Richard Black and Howard White (eds), Targeting Development: Critical Perspectives on the Millennium Development Goals, London: Routledge

UNFPA (2005) State of the World Population 2005: The Promise of Equality - Gender Equity, Reproductive Health and the MDGs, New York: United Nations Population Fund

UNICEF (2007) The State of the World's Children 2008: Child Survival, New York: United Nations Children's Fund

UNICEF (2006) Women and Children: The Double Dividend of Gender Equality. State of the World's Children 2007, New York: United Nations Children's Fund

WHO (2007) Engaging Men and Boys in Changing Gender-based Inequity in Health: Evidence from Programme Interventions, Geneva: World Health Organization

World Bank (2007a) Gender Action Plan: Gender Equality as Smart Economics, Washington DC: World Bank

World Bank (2007b) World Development Report 2008: Agriculture for Development, Washington DC: World Bank

World Bank (2001) Engendering Development Through Gender Equality in Rights, Resources and Voice, Washington DC: World Bank 